\title{
Effects of menthol on thermoregulatory responses after exercise-induced hyperthermia
}

\author{
Young-Joon Jang ${ }^{1 *}$, Jung-Hyun Kim², Joo-Young Lee ${ }^{1}$ \\ From 15th International Conference on Environmental Ergonomics (ICEE XV) \\ Portsmouth, UK. 28 June - 3 July 2015
}

\begin{abstract}
Introduction
Menthol is a chemical compound stimulating TRPM8 which is activated in relatively cool environment below $28{ }^{\circ} \mathrm{C}$ [1] and induces cooling sensation on human skin [2]. Many researchers have explored menthol's thermophysiological influences on humans. Lee and colleagues [3] found that rectal temperature increased faster and total sweat rate was lower than control when a $0.8 \%$ menthol solution was applied on the upper body. Most researches have focused on menthol application during or before heat exposure, but in the practical situation menthol products are used for relieving thermal discomfort or muscular fatigue after intensive exercise. Therefore, the effects of topical menthol application on physiological responses, including sweat secretion after exercise-induced hyperthermia were investigated in the present study. We hypothesized that menthol application during recovery after exercise would relieve thermal sensation without increasing deep body temperature.
\end{abstract}

\section{Methods}

Ten male subjects participated in this study. The exercise protocol consisted of $15 \mathrm{~min}$ rest on a cycle ergometer at air temperature $\left(\mathrm{T}_{\mathrm{a}}\right)$ of $23{ }^{\circ} \mathrm{C}$ and relative humidity (RH) of $50 \%$, followed by cycling at $\mathrm{T}_{\mathrm{a}} 45{ }^{\circ} \mathrm{C}$ with $50 \% \mathrm{RH}$ until rectal temperature increased $1.5^{\circ} \mathrm{C}$ higher than baseline, and a $1 \mathrm{~h}$ recovery period. At the $10^{\text {th }}$ min of the recovery, menthol or control (lanolin) cream was applied on both arms and legs, except the hands and feet. Skin temperatures, rectal temperature, active sweat gland density (ASGD) on the forearm and thigh, skin blood flow on the forearm and thigh, and subjective perceptions (thermal sensation, thermal

\footnotetext{
* Correspondence: leex3140@snu.ac.kr

'COM:FORT Laboratory, College of Human Ecology, Seoul National University, Seoul, Korea

Full list of author information is available at the end of the article
}

comfort, and rate of perceived exertion) were measured. A peripheral vasomotor tone index was calculated from the difference between forearm and finger temperatures.

\section{Results}

Rectal temperature showed a tendency to be decreased more quickly, the peripheral vasomotor tone index was smaller, and ASGD was also smaller in the menthol condition compared to the control, but the group differences were not statistically significant. Subjects felt cooler in the menthol condition than in control $(\mathrm{P}<$ 0.05 ) but the differences disappeared $30 \mathrm{~min}$ after the topical application.

\section{Conclusion}

A menthol-induced peripheral vasoconstriction and lower sweating has been reported before exercise caused an increase in deep body temperature, which might not be safe for humans in heat. The present results indicate that menthol application on the extremities except the hands and feet during recovery after exercise did not increase rectal temperature but relieved thermal sensation and thermal comfort for 30 minutes. These results suggest that menthol can be effectively applied to sports therapy during recovery.

\section{Authors' details}

'COM:FORT Laboratory, College of Human Ecology, Seoul National University, Seoul, Korea. ${ }^{2}$ National Personal Protective Technology Laboratory (NPPTL), NIOSH/CDC, Pittsburgh, PA, USA.

Published: 14 September 2015

\section{References}

1. Talavera K, Nilius B, Voets T: Neuronal TRP channels: thermometers, pathfinders and life-savers. Trends in Neurosciences 2008, 31(6):287-295.

2. Patel T, Ishiuji Y, Yosipovitch G: Menthol: A refreshing look at this ancient compound. Journal of American Academy of Dermatology 2007, 57(5):873-878. 
3. Lee JY, Nakao K, Bakri I, Tochihara Y: Body regional influences of Lmenthol application on the alleviation of heat strain while wearing firefighter's protective clothing. European Journal of Applied Physiology 2012, 112:2171-2183

doi:10.1186/2046-7648-4-S1-A6

Cite this article as: Jang et al:: Effects of menthol on thermoregulatory responses after exercise-induced hyperthermia. Extreme Physiology \& Medicine 2015 4(Suppl 1):A6.

Submit your next manuscript to BioMed Central and take full advantage of:

- Convenient online submission

- Thorough peer review

- No space constraints or color figure charges

- Immediate publication on acceptance

- Inclusion in PubMed, CAS, Scopus and Google Scholar

- Research which is freely available for redistribution

Submit your manuscript at www.biomedcentral.com/submit
C Biomed Central 